\title{
Synthesis of morpholinium salts based on chloroacylated derivatives of dihydroquercetin
}

\author{
C Anton O. Pozdeev, ${ }^{1}$ Alexander M. Koroteev, ${ }^{1}$ Sofia N. Pimankina, ${ }^{1}$ \\ Mikhail P. Koroteev, ${ }^{1 *}$ and Evgeny N. Ofitserov ${ }^{2+}$ \\ ${ }^{1}$ Department of Organic Chemistry. Institute of Biology and Chemistry. Moscow Pedagogical State \\ University. Kibalchicha St., 6, Bldg. 2. Moscow, 129164. Russia. \\ Phone: +7 (495)682-02-45.E-mail: Starmansky@mail.ru \\ ${ }^{2}$ Department of Chemistry and Technology of Biomedical Preparations. Faculty of Chemical and \\ Pharmaceutical Technologies and Biomedical Preparations. Russian University of Chemical Technology \\ D.I. Mendeleev. Miusskaya Sq., 9. Moscow, 125047. Russia. Phone: +7 (495) 978-32-61. \\ E-mail: ofitser@mail.ru
}

*Supervising author; ${ }^{+}$Corresponding author Keywords: acylation, morpholine, dihydroquercetin (DHA), acyl and benzyl derivatives of DHQ.

\begin{abstract}
The flavonoid dihydroquercetin and its esterified derivatives possess various biological activities and are widely used as dietary supplements and in pharmacology. A significant disadvantage of this flavonoid is its low solubility in water at ordinary temperatures of up to $0.03 \%$, which negatively affects its biological activity. Nature overcomes this problem by glycosylation, sulfation, and phosphorylation. In chemistry and pharmacology to overcome this problem, there are several synthetic approaches. For dihydroquercetin (DHQ) is the inclusion of DHQ in the cyclodextrin matrix or the formation of a complex of DHQ with basic natural amino acids. In this paper, a method is proposed for obtaining water-soluble morpholinium salts based on chloroacylated derivatives of DHQ. The acylation reaction was carried out in dioxane, pyridine was used as an acceptor of choric hydrogen. The target compounds were obtained with a yield of $68-79 \%$. As a result, chlorinated derivatives based on DHQ and its acyl and benzyl derivatives were synthesized. These derivatives in the interaction with morpholine form its salts, which, as it turned out, have a high water solubility. Pentamorpholine salt of DHQ had the highest solubility in water, up to $6.5 \%$ at room temperature, which is 200 times more soluble than the original DHQ. The proposed synthetic approach to increase the water solubility of acyl derivatives of DHQ can be extended using other nitrogenous bases and other haloacyl derivatives of DHQ.
\end{abstract}

\section{References}

[1] E. Nifant'ev, M.C. Krymchak, M.P. Koroteev, A.M. Koroteev, T.S. Kukhareva, and L.K. Vasyanina. Exhaustive Acylation of Dihydroquercetin. Russian Journal of General Chemistry. 2011. Vol.81. No.1. P.102-105.

[2] A.M. Koroteev, A.O. Pozdeev, M.P. Koroteev, I.I. Levina, L.K. Vasyanina, G.Z. Kaziev, E.E. Nifantyev. Science and School. 2012. No.3. P.181-184. (russian)

[3] E.E. Nifantyev, A.M. Koroteev, A.O. Pozdeev and others. Chem. Farm. Journal. 2015. Vol.49. No.2. P.82-85. (russian)

[4] A.M. Koroteev, G.Z. Kaziev, M.P. Koroteev, E.E. Nifantyev, V.M. Shutov. Water-soluble complex compound including dihydroquercetin-cyclodextrin and method for its preparing. RF PATENT for invention № 2396077. Reg. in the State the register of inventions of the Russian Federation on August 10. 2010. (russian)

[5] A. Gordon, R. Ford. Satellite chemist. Moscow: Moscow. 1976. P.437-444. (russian)

[6] Aft H. Chemistry of dihydroquercetin. I. Acetate derivatives. J. Org. Chem. 1961. Vol.26. P.1958-1963.

[7] A.O. Pozdeev, A.M. Koroteev, S.N. Pimankina, M.P. Koroteev, and E.N. Ofitserov. Synthesis of new acyl derivatives of dihydroquercetin and catechin. Butlerov Communications. 2018. Vol.54. No.6. P.116123. P.116-123. DOI: 10.37952/ROI-jbc-01/18-54-6-116 